\title{
EL CONVENTO DE SANTO DOMINGO EN CARTAGENA DE INDIAS
}

María Fernanda Reyes Rodríguez*

Patio interior del Convento de Santo Domingo de Cartagena. Arquitecta Liliana Rueda Cáceres, Cartagena, 2009. Tomada de "Conventos dominicos que construyeron un país" Bucaramanga, USTA, 2010

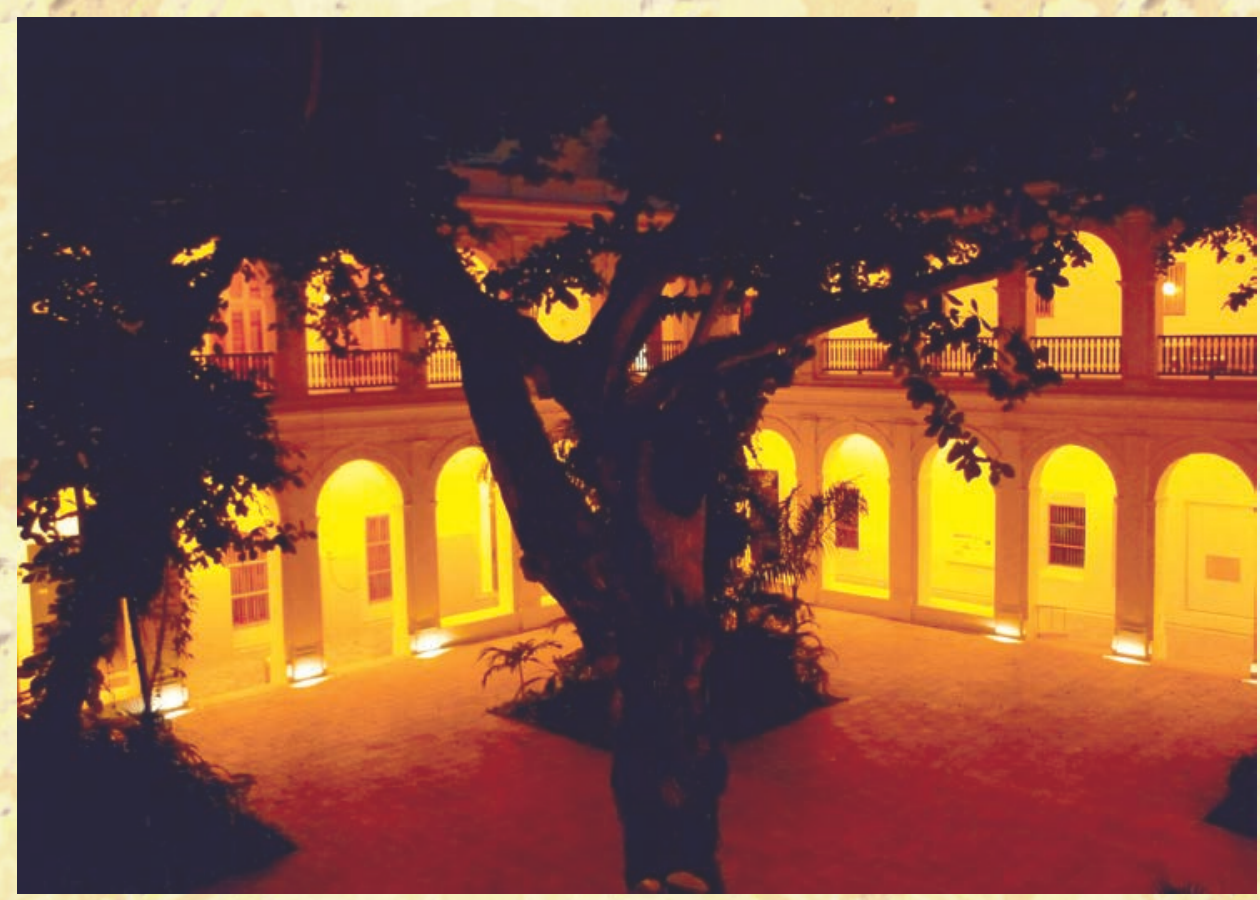

\section{RESUMEN}

Este artículo forma parte de la investigación La arquitectura dominicana y la formación religiosa, social y cultural de Colombia a doscientos años de la Independencia, realizada entre 2009 y 2010 de manera conjunta por las tres facultades de arquitectura de la Universidad Santo Tomás; el proyecto fue desarrollado por iniciativa de la seccional de Bucaramanga, bajo la dirección del historiador William Elvis Plata Quezada. Producto de la búsqueda y selección de fuentes primarias y secundarias, se preparó el acervo documental que haría parte de los insumos empleados en el apartado dedicado al Convento de San José de Cartagena de Indias, labor que estuvo a cargo de la historiadora Piedad Lucía Otero Uribe, en el Archivo de la Provincia de San Luis Bertrán de la Orden de Predicadores y en el Archivo General de la Nación.

El artículo da cuenta de la erección del primer convento cartagenero, establecido por la Orden de Predicadores bajo la advocación de San José, argumentando que su núcleo inicial fundacional corresponde a 1539, fecha que registra más allá de un proyecto material, así fuera de factura modesta, un primer intento de congregación que se consolida diez años después con el arribo de Fray José de Robles. El convento de Santo Domingo en Cartagena de Indias es un ejemplo afortunado de restauración de un inmueble de valor patrimonial en territorio colómbiano, proyecto a cargo del arquitecto Alberto Samudio Trallero, el cual se enmarca en el Programa de Patrimonio Cultural desarrollado por la Agencia Española de Cooperación Internacional, cuyo equipo de trabajo tuvo la tarea de intervenir un área de II.175 metros cuadrados, en un espacio de dos años, desde 2000 hasta el 2004.

\section{PALABRAS CLAVE:}

Orden de Predicadores, Cartagena de Indias, Convento de San José 


\section{THE SANTO DOMINGO CONVENT PLACED IN CARTAGENA DE INDIAS}

María Fernanda Reyes Rodríguez*

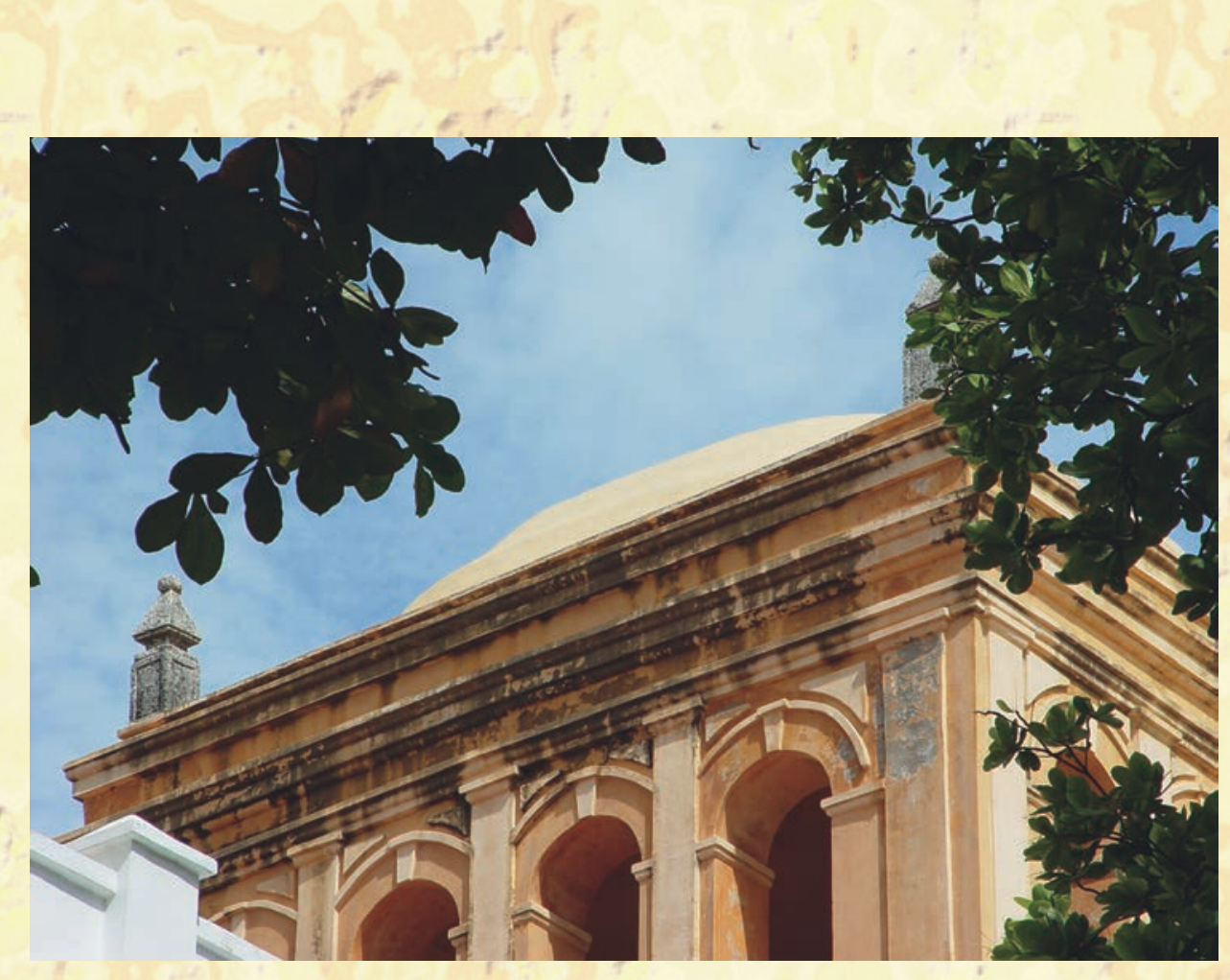

Historiadora de la Universidad Industrial de Santander, candidata a magíster en Historia de la misma universidad. Docente y Coordinadora Editorial de la Revista M de la Facultad de Arquitectura de la Universidad Santo Tomás Bucaramanga.

\section{ABSTRACT}

This article is part of the research study Dominican architecture and the religious, social and cultural formation in Colombia two hundred years from the independence, it was carried out between 2009 and 2010 jointly by the three faculties of architecture at the Universidad Santo Tomas; the project was developed due to an inniciative of the branch of Bucaramanga, under the direction of historian William Elvis Plata Quezada. Product of the search and selection of primary and secondary sources, a documentary heritage was prepared, which would be part of the raw material used in the section dedicated to the Convent of San José of Cartagena de Indias, this piece of work was conducted by historian Piedad Lucia Otero Uribe, in the Archives of the Province of San Luis Bertran of the Order of Preachers and the General National Archives.

The article reports on the erection of the first convent of Cartagena, established by the Order of Preachers under the patronage of San Jose, arguing that their initial foundational core corresponds to I539, date when it registered something beyond a material project, no matter its humble nature, a first attempt of congregation was consolidated ten years later with the arrival of Fray José de Robles. The Santo Domingo convent placed in Cartagena de Indias is a lucky restoration sample of proper equity in Colombia, such project developed by architect Alberto Samudio Trallero, which is framed in Cultural Property Program developed by Agencia Española de Cooperación Internacional whose teamwork had the aim of building II, I 75 square metres area for two years, from 2000 to 2004.

\section{KEY WORDS:}

Order of Preachers, Cartagena de Indias, Saint Joseph Convent. 


\section{INTRODUCCIÓN}

Fueron los Dominicos los encargados del establecimiento de las primeras misiones en territorio de la actual Colombia. En diciembre de 1528, dos años después de fundada Santa Marta por Rodrigo de Bastidas, desembarcaron en el puerto los primeros frailes de la Orden de Predicadores con el gobernador García de Lerma y el I4 de enero de I533 llegaron a Calamarí junto con Pedro de Heredia los dominicos Fr. Diego Ramírez y Fr. Luis de Orduña; cinco meses después se fundaría la ciudad'.

Poco a poco los frailes al recorrer la tierra firme establecieron templos y conventos. En una primera etapa se trataba de construcciones sencillas elaboradas con materiales poco perdurables, generalmente paja y cañas que fácilmente eran destruidas por vendavales e incendios. Avances y retrocesos marcaron el ritmo de esta primera etapa de formación de ciudades y pueblos, en la cual no sólo se experimentó una tosca arquitectura sino también una tensa situación entre las autoridades civiles y eclesiásticas.

Fr. Orlando Rueda Acevedo, menciona que a medida que las posibilidades lo permitían, los frailes fueron dando una categoría sobresaliente a sus conventos y templos, cuya presencia era ya, por sí misma, una enseñanza sobre la dignidad de la religión. Ubica en una línea del tiempo el surgimiento de los conventos establecidos por la Orden de Predicadores, el primero de los cuales corresponde al de Santo Domingo de Guzmán en Santa Marta (I529), San José en Cartagena (I539), Santo Tomás de Aquino en Tocaima (I544), Vélez (I549), Nuestra Señora del Rosario en Santa Fe (I550), Santo Domingo de Guzmán en Tunja (I55 I), San Sebastián en Popayán (I552), Ecce Hommo (I620), Nuestra Señora del Rosario de Chiquinquirá (1636), La Martinica en Villa de Leyva (1855) y Santo Tomás de Aquino en Zapoteca $(1913)^{2}$.

Imagen I. Acuarela de Santo Domingo, obsequiada por Rafael Lelarge al R. P. Enrique Báez, Cartagena, Marzo 8 de 1930. Fuente: BÁEZ ARENALES, Enrique. O.P. La Orden Dominicana en Colombia. (Obra Inédita). Paipa, Enero de 1950. Tomo VI. Conventos y casas dominicas de Panamá, Cartagena, Santo Marta, Mompox, Riohacha, Valledupar, Tolú y Santo Ecce-Homo. Archivo de la Provincia de San Luis Bertrán de Colombia de la Orden de Predicadores, Fondo San Antonino, Sección Personajes, Báez. Tomada de "Conventos Dominicanos que construyeron un país" Bucaramanga: USTA, 2010

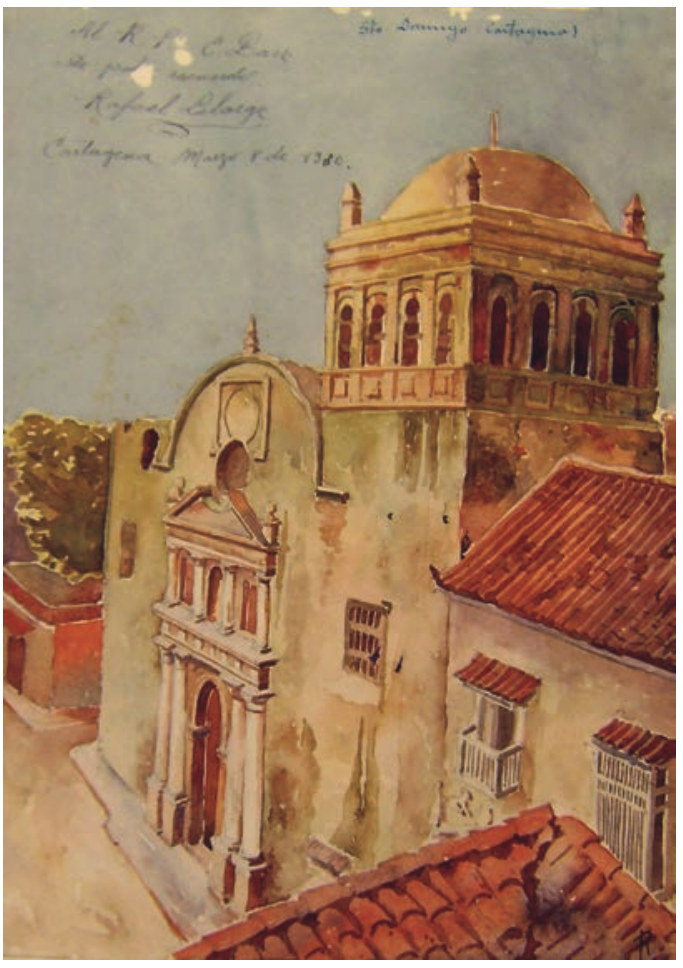

ARIZA, Alberto. O. P. Los Dominicos en Colombia. Bogotá, Provincia de San Luis Bertrán, 1993. Tomo I. p. 239

RUEDA ACEVEDO, Orlando. O. P. Los dominicos y el arte en la evangelización del Nuevo Reino de Granada. en José Barrado Barquilla (Ed.) Los Dominicos y el Nuevo Mundo Siglos XVIII-XIX. Actas del IV Congreso Internacional, Bogotá, 6-10 septiembre de 1993. Salamanca, Editorial San Esteban, 1995. pp. 567-568 
Por su parte, Alberto Corradine Angulo argumenta que la erección de obras elaboradas con materiales resistentes, para sustituir las existentes en paja y bahareque perdura a veces hasta los inicios del siglo XVII, como quedó demostrado a su parecer con el incendio que arrasó casi por completo a Cartagena en el ataque del corsario Francisco Drake en 1586; afirma que si bien, un gran número de conventos fueron establecidos durante la segunda mitad del siglo XVI, su fundación no pasó del plano canónico, pues casi todas las comunidades tomaron casas en arriendo para su funcionamiento o emplearon construcciones transitorias a la espera de mejores oportunidades para levantar edificios de algún significado³.

Como se verá más adelante, el proceso constructivo del convento e iglesia de San José en Cartagena de Indias a cargo de la Orden de Predicadores tardó casi tres siglos, no así el inicio de la vida conventual cuyo núcleo puede rastrearse en enero de I539. Este hecho es clave para entender que más allá del edificio, lo que debe primar es el estudio del convento como entidad social, su incidencia en el devenir de Cartagena y las relaciones, influencias y tensiones, que se mantienen o no en el tiempo, de los frailes con la comunidad en general; sin embargo, en este artículo, el énfasis está puesto en aspectos relacionados con su desarrollo constructivo.

Antonio García Rubial estudia el convento y su función social, caracterizándolo como el núcleo básico en la organización de las órdenes mendicantes, en cuyo seno se forjaron y plasmaron todos los factores, elementos y características de la congregación novohispana. Estos núcleos estaban formados por un grupo de personas que vivían bajo un mismo techo y cuyas relaciones entre sí y con el resto de la congregación estaban reglamentadas por un régimen jurídico propio. El convento era la reunión de un número de religiosos sometidos a una regla y a unas constituciones y por tanto, el edificio donde habitaban tomó el mismo nombre. Para García Rubial, la relación directa con la sociedad, motivó la formación de dos tipos de unidades conventuales: rurales y urbanas, las primeras asociadas a las casas de los pueblos de indios, las segundas a las villas y ciudades de españoles ${ }^{4}$. Adentrarse en el estudio del convento posibilita, por tanto, el entendimiento de los patrones de vida no sólo de la comunidad religiosa que se ha establecido en él, sino también, el conjunto de valores, relaciones y sentimientos de la sociedad en su conjunto.

\section{LOS DOMINICOS EN CARTAGENA DE INDIAS}

No se puede desconocer la labor de evangelización adelantada por la Orden de Predicadores en Cartagena de Indias, no sólo en el casco urbano, sino también en zonas apartadas en las cuales se establecieron doctrinas, centros en los que se reunió a la población indígena con el objeto principal de convertirlos a la fe católica. Los grupos indígenas asentados en el territorio que posteriormente se denominó gobernación de Cartagena, pertenecían a diversas familias lingüísticas y presentaban diferentes niveles de desarrollo tecnológico, de organización social y política, logrando su adaptación en los distintos ambientes del lugar, entre los que se encontraban el marino, ribereño, lacustre, sabanero y selvático ${ }^{5}$.

Aunque el establecimiento del convento e iglesia de los dominicos en la ciudad, al menos en su parte constructiva avanzaba lentamente, con muchos tropiezos y penurias económicas, la evangelización lo hizo a pasos agigantados, pues un año después del arribo de la Orden de Predicadores a la costa Caribe, ya se había producido la reducción de cuatro pueblos

3 CORRADINE ANGULO, Alberto. La arquitectura colonial. en Manual de Historia de Colombia Tomo I. Bogotá, Instituto Colombiano de Cultura, 1978. pp. 421-430

4 GARCÍA RUBIAL, ANTONIO. Capítulo 4. El convento: su función social. En: El Convento Agustino y la sociedad novohispana 1533-1630. México, Universidad Nacional Autónoma de México, 1989. pp. 109-I I0

5 CONDE CALDERÓN, Jorge. Espacio, Sociedad y Conflictos en la Provincia de Cartagena 1740-1815. Barranquilla, Fondo de Publicaciones de la Universidad del Atlántico, Colección de ciencias sociales y económicas Rodrigo Noguera Barreneche, 1999. pp. I0-II 
en los alrededores de Cartagena: Carex, Mahates, Turbaco y Bahaire que aumentaron con dos más en Cipagua y Malambo en I534, llegando al número de 20 para I57I, momento en el que se desarrolló el primer capítulo de la Provincia de San Antonino'.

Algunas de estas doctrinas se atribuyen a San Luis Bertrán, llegado a Cartagena en I 562. Por su labor de cura doctrinero en el pueblo de Tubará, adquirió entre aquella gente opinión de gran santo. Llegó a bautizar en espacio de tres años a más de 1500 indios de su propia mano, aunque en la conversión de este pueblo se dice que pasó grandes trabajos. Se tiene noticia de que su morada allí fue convertida en ermita a donde no sólo acudían los indios, sino también los españoles, clérigos y frailes de la comarca en busca de auxilios y favores ${ }^{7}$. En I57I el Convento de San José tenía a su cargo las reducciones de la Isla de Carex, Caron, Matarapa, Cocon, Cazpique, Mahates, Zipacúa, Oca, Zambo, Canapote, Bahaire, Turbaco, Tocana, Mazaguapo, Guaspates, Tubará, Usiacurí, Piojón, Malambó y Timiriguaco. (Ver Cuadro I.) $)^{8}$

Cuadro I. Descripción de algunos pueblos en los cuales se establecieron doctrinas a cargo de los Dominicos

\begin{tabular}{|l|l|}
\hline \multicolumn{1}{|c|}{ PUEBLO } & \multicolumn{1}{c|}{ DESCRIPCIÓN } \\
\hline Timiriguaco & $\begin{array}{l}\text { Pueblo de la provincia y gobierno de Cartagena en el Nuevo Reino de Granada, situado a la orilla de } \\
\text { un arroyo, 8 leguas al sur de su capital. }\end{array}$ \\
\hline Tubará & $\begin{array}{l}\text { Pueblo de la provincia y gobierno de Cartagena en el Nuevo Reino de Granada, célebre por la } \\
\text { circunstancia de haber sido cura doctrinero en él San Luis Bertrán que redujo a sus naturales a la fe } \\
\text { católica y quedó desde entonces el curato al cuidado de los religiosos de la Orden de Predicadores, } \\
\text { hasta que el obispo don Luis Ronquillo de Córdoba, la adjudicó a los clérigos, sobre que hubo un } \\
\text { pleito muy disputado y se mandó por el rey que volviese a aquellos religiosos. }\end{array}$ \\
\hline $\begin{array}{l}\text { Turbaco o } \\
\text { Calamari }\end{array}$ & $\begin{array}{l}\text { Pueblo de la provincia y gobierno de Cartagena en el Nuevo Reino de Granada, en que fue cura } \\
\text { doctrinero San Luis Bertrán, está a una legua de la capital y en tiempo de los indios gentiles era } \\
\text { ciudad muy populosa y grande pues tenía más de 2000 almas de vecindario. La conquistó a costa de } \\
\text { muchos trabajos y combates el Adelantado D. Pedro de Heredia y conserva el nombre del cacique } \\
\text { o Regulo señor de ella; es de temperamento cálido pero sano y muy fértil, especialmente en maíz. } \\
\text { Está en la coste al SE, cerca de la Ciénaga de Tesca. Es célebre por la batalla que Alonso de Ojeda } \\
\text { dio a sus naturales el año de I6IO en que quedó derrotado; Pedro de Heredia les dio otras tres muy } \\
\text { sangrientas, logrando salir victorioso e incendiar el pueblo para escarmiento. }\end{array}$ \\
\hline Usiacurí & $\begin{array}{l}\text { Pueblo de la provincia y gobierno de Cartagena del Nuevo Reino de Granada, situado a la orilla del } \\
\text { caño que sale de la Ciénaga de Turbaco al mar. }\end{array}$ \\
\hline
\end{tabular}

Fuente: Diccionario Geográfico-Histórico de las Indias Occidentales o América. Es a saber: de los Reinos del Perú, Nueva España, Tierra Firme, Chile y el Nuevo Reino de Granada. Escrito por el Coronel Don Antonio de Alcedo, Capitán de Reales Guardias Españolas, de la Real Academia de Historia. Tomo V. Madrid, Imprenta de Manuel González, I 789.

\section{EL EDIFICIO CONVENTUAL}

\section{Primera etapa: Núcleo fundacional y primer claustro pajizo (I539-I549)}

Fray Alonso de Zamora en su Historia de la Provincia de San Antonino del Nuevo Reino de Granada, cuya primera edición corresponde a I70I, asegura que el convento de San José de Cartagena es más antiguo que la erección de su catedral; según refiere el cronista

6 DÍAZ PARDO, Camilo. La importancia de la Orden de los Predicadores en el contexto socio histórico de Cartagena. Barranquilla, Universidad del Norte, 2003

7 Historia de la vida, virtudes y milagros del Beato Luis Bertrán de la Orden de Predicadores. Por el P. M. Fr. Vicente Saborit, Regente de los estudios del Real Convento de Predicadores de Valencia. Dedicado al muy ilustre señor Don Pedro Quexal. Año de 165I. Capítulo XVIII. De lo que el B. Luis Bertrán hizo en Tubará. De San José fue enviado a Tubará a reducir a aquella gente al conocimiento de Dios. ff. 66-70

8 DE ZAMORA, Alonso. O. P. Historia de la Provincia de San Antonino del Nuevo Reino de Granada. Bogotá, Editorial Kelly, 1980 (I70I) p. 196 
dominico, el convento se fundó con la misma ciudad porque los religiosos de la Orden de Predicadores que vinieron con Pedro de Heredia, fueron los primeros sacerdotes que administraron en ella los santos sacramentos ${ }^{9}$. Es de suponerse que estos oficios se adelantaron en ranchos con techumbre de paja o palma, pero no compartimos la idea que al tiempo que se fundó la ciudad se erigió el convento, así su estructura fuera primitiva; si bien se tiene registro de los nombres de los frailes dominicos que acompañaron a Heredia al momento de la fundación de Cartagena en $1533^{10}$ y de los innumerables esfuerzos que se hicieron desde esta fecha para el establecimiento de la edificación, compuesta por templo e iglesia y que en adelante puede catalogarse como un conjunto monumental, resulta exagerado atribuir su erección en la misma fecha y, por tanto, es necesario buscar los orígenes del convento dominico de Cartagena de Indias, amparándonos en otros autores y fuentes; pero incluso al hacerlo, encontramos contradicciones y la mención de fechas que van desde 1539 hasta 1552 como posibles años de su fundación. Lo anterior ocurre porque para algunos autores, la existencia del convento está dada exclusivamente por la aparición del edificio y la certeza de su emplazamiento, y descartan el hecho fundamental de su concepción y de la constitución de una comunidad dominicana con vida común, que es la esencia de un convento.

Intentaremos presentar a continuación datos relevantes que nos podrían indicar que la erección y primer emplazamiento del convento e iglesia de San José, corresponde a una fecha cercana a I 538 que denominaremos primera etapa.

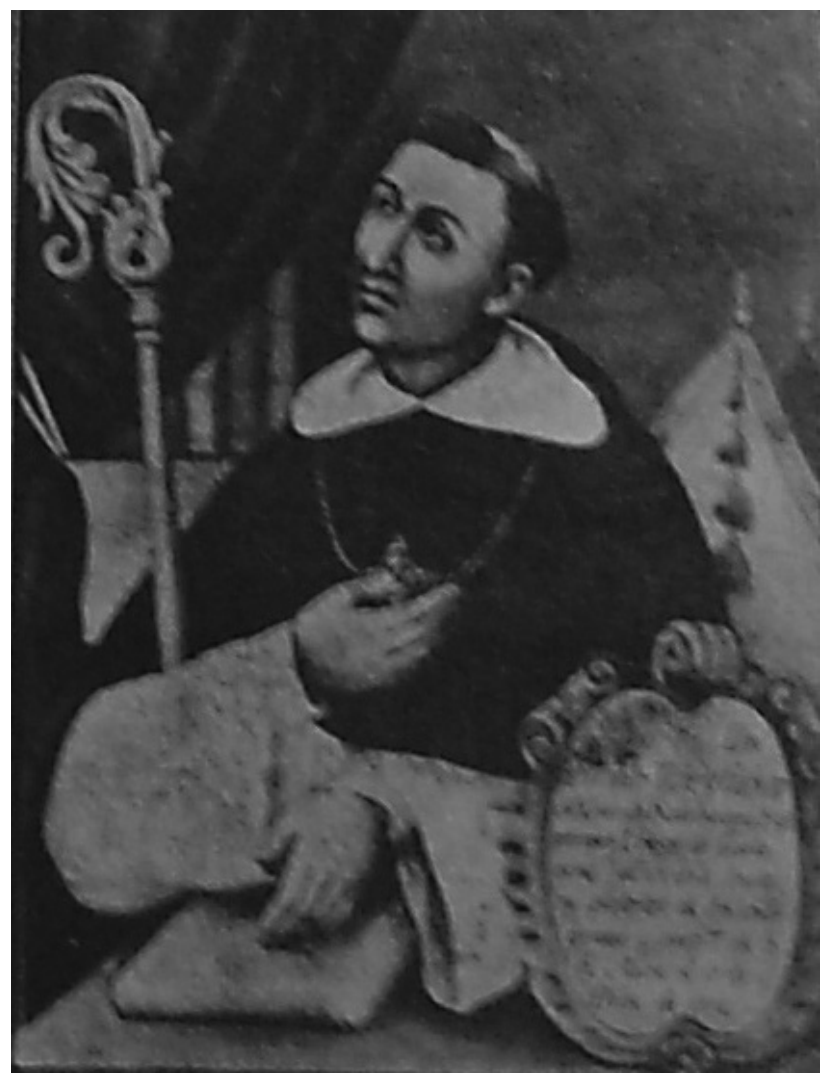

9 lbíd., p. 63

10 Los frailes dominicos que acompañaron a Heredia el I 4 de enero de 1533 cuando desembarcó en Calamarí fueron Diego Ramírez, Luis de Orduña, Domingo de Heredia y el franciscano Clemente Mariana.
IMAGEN 2. Fray Tomás del Toro y Cabero. Fuente: BAEZ ARENALES, Enrique. O.P. La Orden Dominicana en Colombia. Obra Inédita. Paipa, Enero de 1950. Tomo VI. Conventos y casas dominicas de Panamá, Cartagena, Santa Marta, Mompox, Riohacha Valledupar, Tolú y Santo Ecce-Homo. Archivo de la Provincia de San Luis Bertrán de Colombia de la Orden de Predicadores, Fondo San Antonino, Sección Personajes, Báez. 
El 3 de septiembre de 1533 fue elegido como primer obispo de Cartagena el dominico Fr. Tomás del Toro y Cabero quien ocupó la silla episcopal en abril del año siguiente. Acompañado por los frailes Lucas de la Vega, Miguel Ruiz y Justo del Hoyo se estableció en la ciudad, sin contar por el momento con licencia para fundar un monasterio" . Juan Friede refiere que para 1535 Cartagena contaba ya con 800 vecinos provenientes de Santo Domingo y España $^{12}$, lo que puede darnos una idea de la necesidad apremiante que había en Cartagena para el establecimiento definitivo de una comunidad religiosa que se encargara no sólo de las doctrinas en los pueblos de indios, sino de los asuntos espirituales y la celebración de eucaristías en el casco urbano, aspectos que obligaban a la urgente erección del convento.

La gestión para la erección del convento de San José recayó en manos del sucesor de Toro y Cabero, Fr. Jerónimo de Loaisa y Carvajal, quien según refiere Fr. Enrique Báez, se embarcó a América en 1528 con el P. Tomás Ortiz, siendo uno de los 21 dominicos que en febrero de 1529 llegaron a Santa Marta, retornó a España en 1534 para interceder por los indígenas ${ }^{13}$, allí fue preconizado segundo obispo de la ciudad el 5 de diciembre de $1537^{14}$. Fray Jerónimo de Loaisa llegó a Cartagena, llevando en su poder una Cédula Real expedida en Valladolid en mayo de I538, por medio de la cual se le facultaba para construir el monasterio dominico:

"Nuestro gobernador o Juez de residencia de la Provincia de Cartagena: Fray Jeronimo de Loaysa de la Orden de Santo Domingo y obispo confirmado de esa provincia me ha hecho relación que lleva a ella algunos religiosos de su orden con voluntad de hacer en esa provincia un monasterio, y me suplica le hiciese merced de mandaros que en la parte donde a él y a vos os pareciere que convenga hacerse el dicho monasterio, le señalares sitio conveniente para ello y proveyeres que los indios comarcanos ayudasen a la obra y edificio de el o como la mi merced fuese, y yo acatando cuanto Dios nuestro señor para servicio deje hacer el dicho monasterio, tuvelo por bien, por ende os mando que en la parte que a vos y al dicho obispo pareciere que conviene se haga el dicho monasterio le deis y señaleis sitio conveniente en que se puede vacer y procureis que los indios comarcanos ayuden a la obra y edificio del con la menor vejación suya que se pueda, fecha en la villa de Valladolid a treinta y uno de mayo de mil e quinientos e treynta e ocho"/5.

Fray Alberto Ariza menciona que con esta autorización, aunque el obispo llegó a Cartagena en diciembre de 1539, nueve religiosos iniciaron vida conventual en la residencia misional a principios del mismo año, aunque el convento no se fundaba aún formalmente ${ }^{16}$. De este fragmento llaman la atención tres aspectos: que el obispo Jerónimo de Loaisa llegó a Cartagena en diciembre de 1539; para enero de 1539 nueve religiosos iniciaron vida conventual y que el convento no se establecía aún.

El segundo aspecto indica el punto de partida de la congregación, de la reunión de un número de frailes de la Orden de Predicadores, nueve en este caso, que vivían ya bajo

II ARIZA Op. Cit., p. 239; SAMUDIO TRALLERO, Alberto. Convento de Santo Domingo. Investigación histórica (Inédita) Cartagena de Indias, Agencia Española de Cooperación Internacional AECl, Arquidiócesis de Cartagena, 200I.

I2 FRIEDE, Juan. La conquista del territorio y el poblamiento. en Manual de Historia de Colombia Tomo I, Bogotá, Instituto Colombiano de Cultura, 1978. p. 137

I3 BÁEZ, Enrique. O. P. La Orden Dominicana en Colombia (Obra Inédita) Paipa, I 950. Tomo VI. Conventos y casas dominicanas de Panamá, Cartagena, Santa Marta, Mompox, Riohacha, Valledupar, Tolú y Santo Ecce-Homo. Archivo de la Provincia de San Luis Bertrán de Colombia de la Orden de Predicadores. Bogotá, Fondo San Antonino, Sección personajes, Baeza.

14 ARIZA Op. Cit., p. 239

I5 Real Cédula al Gobernador de Cartagena para que señale sitio al monasterio de Dominicos, Valladolid, 3 I de mayo de I 538. En Archivo General de Indias, Sevilla, España, Santa Fe, 987, Libro II, f. 45

16 ARIZA Op. Cit., p. 240 
ciertas reglas en un lugar de la ciudad a comienzos de 1539; aunque hasta el momento se desconozca el sitio exacto de su ubicación, este lugar ya se puede llamar convento.

En la guía descriptiva que lleva por título Cartagena y sus cercanías publicada en 1912 , se encuentra algún indicio de lo que pudo haber sido el primer emplazamiento del convento, ubicado en un punto donde a la fecha existía una carnicería; en este documento se menciona que Loaysa entró a la ciudad a fines de 1538, es decir un año antes del propuesto por Ariza, quien como ya hemos dicho, notifica su llegada en diciembre de 1539, y afirma con fundamento, que la erección del convento tuvo efecto en $1539^{17}$. Más adelante encontramos, que la fecha de 1539 la toma de la Historia Civil y eclesiástica de José Manuel Groot, quien menciona que el obispo Loaisa, dispuso la fundación del convento de los dominicos para lo cual donó, con obligación de misas, el licenciado Juan Materano, unos solares en la plazuela que llamaban del juez por haber tenido allí su casa el licenciado Santacruz y que después se llamó de la (yerba) hierba. A continuación refiere que con los mil pesos librados por el Rey, construyó una pequeña iglesia con vivienda acomodada para los religiosos, de la cual tomó posesión con título de Prior en 1539, el Padre Fray José de Robles quien la denominó San José ${ }^{18}$.

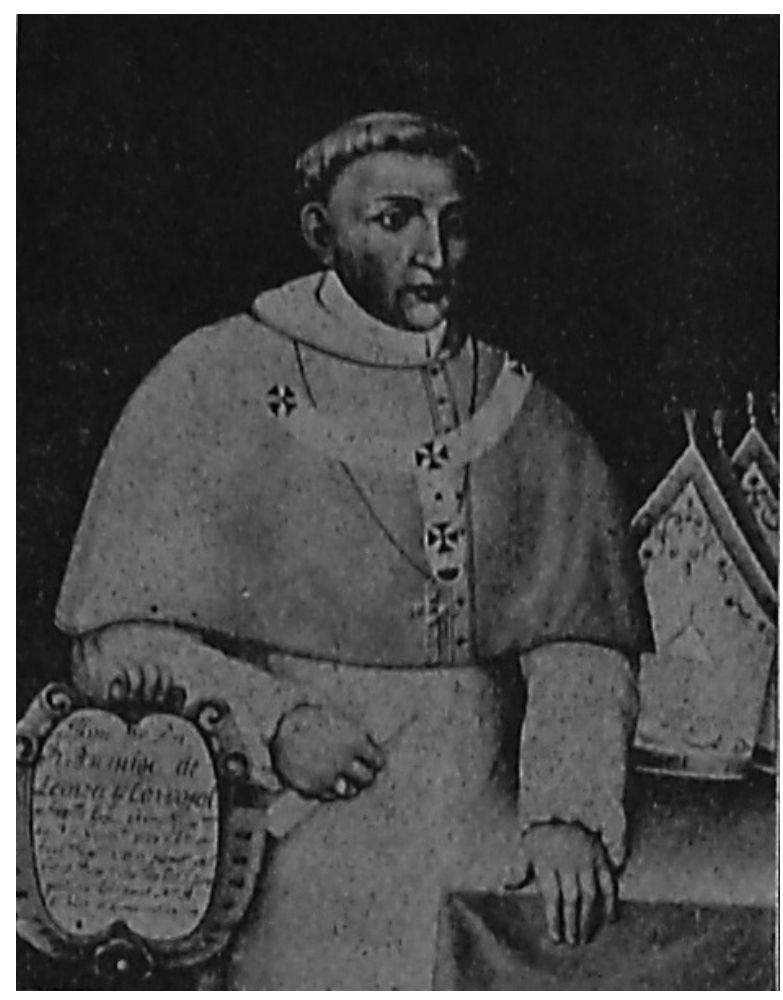

La mención del nombre de plaza del juez por haber tenido allí su residencia el licenciado Santa Cruz, es puesta en duda por Enrique Marco Dorta quien infiere que el lugar no pudo deber su nombre a esta circunstancia, pues este juez de residencia llegó a Cartagena en fecha posterior a 153919. Sin embargo, encontramos en Friede una referencia que indica que a principios de junio de 1539 Jiménez de Quesada, Sebastián de Belalcázar y Nicolás de Federmán en compañía de algunos conquistadores, llegaron a Cartagena a mediados del mismo mes, donde iniciaron un pleito ante el licenciado Santa Cruz quien estaba en
IMAGEN 3. Fray Jerónimo de Loaisa y Carvajal. Fuente: BAEZ ARENALES, Enrique. O.P. La Orden Dominicana en Colombia. Obra Inédita. Paipa, Enero de 1950. Tomo VI. Conventos y casas dominicas de Panamá, Cartagena, Santa Marta, Mompox, Riohacha Valledupar, Tolú y Santo Ecce-Homo. Archivo de la Provincia de San Luis Bertrán de Colombia de la Orden de Predicadores, Fondo San Antonino, Sección Personajes, Báez.

17 URUETA, José P.; GUTIÉRREZ DE PIÑERES, Eduardo. Cartagena y sus cercanías. Guía descriptiva. Cartagena, Tipografía de Vapor Mogollón, 1912. p. 167

18 Ibíd. p. 168. Basado en la historia civil y eclesiástica de José Manuel Groot.

19 MARCO DORTA, Enrique. Cartagena de Indias puerto y plaza fuerte. Cartagena, Alfonso Amado Editor, 1960, p. 33 
aquel puerto tomando residencia a Pedro de Heredia, ausente en España ${ }^{20}$. Por su parte, Alberto Samudio Trallero refiere la llegada de este funcionario a fines de junio de 1538 para abrir juicio de residencia contra Juan de Vadillo y proseguir el que éste había iniciado contra Pedro de Heredia ${ }^{21}$. Lo anterior es útil para establecer el posible emplazamiento del primer convento de estructura rudimentaria.

Báez señala que en ese mismo año de 1539, el obispo Loaisa en asocio con el Padre Fray José de Robles, fundó el convento de San José, dejó además consignados los nombres de sus padres fundadores entre los que se cuentan los frailes Juan de Ávila, Juan de Chávez y Juan de $Z^{2 e^{22}}$. Además de estos nombres se hace mención en la misma fecha, de los frailes Diego Ramírez, Luis de Orduña, Bartolomé de Ojeda y Martín de los Ángeles como gestores del convento de San Joséz ${ }^{3}$. Hasta este punto coincidimos con los autores en que Fray Jerónimo de Loaisa fue el gestor de la iglesia y convento de los dominicos, aunque en este caso tendríamos que agregar, si se acepta la fecha de 1539, que más allá de un proyecto material, así fuera de factura modesta, de lo que se trató fue de la creación de la comunidad conventual.

El cumplimiento de las Leyes Nuevas de 1542, disposiciones por medio de las cuales la corona española en cabeza de Carlos V, buscaba reglamentar las tirantes e inequitativas relaciones entre indígenas y españoles, denunciadas con suficiencia por el Fraile dominico Bartolomé de las Casas, que entonces hacía parte de la Corte ${ }^{24}$, recayó en América en las manos del licenciado Miguel Díez de Armendáriz, encargado de imponer esta reforma. Una de las instrucciones impartidas a Armendáriz consistía en dar informe de los trabajos adelantados por los religiosos enviados a Santa Marta y Cartagena y sobre sus edificios y monasterios. Armendáriz que llegó a Cartagena a fines de I 544 y permaneció allí hasta 1547, informó que únicamente los de la religión de Santo Domingo habían hecho "muchas reducciones de los naturales a la fe católica", que en sus pueblos tenían algunas iglesias con doctrineros y en las dos ciudades principales dos monasterios, cuyos edificios "proseguían con muy buenos principios" 25 . Este dato refuerza la existencia material del primer convento de dominicos en Cartagena, entre 1545 y 1546, de esa pequeña iglesia con aposentos para los frailes que inició Loaisa en 1539 y que se consolidó con los esfuerzos del Padre Robles diez años después.

\section{Segunda etapa: Formalización del núcleo conventual}

\section{(I549 - I552)}

La selección de esta segunda etapa encuentra asidero en una inconsistencia que Fray Alberto Ariza advierte en Zamora: se trata de la presencia de Loaisa y Robles simultáneamente en Cartagena en 1539 fundando el convento, pues como bien lo explica Ariza, este último sólo llega a la ciudad a fines de septiembre de 1549, diez años después de lo que anteriormente hemos denominado su primer núcleo fundacional. Ariza afirma que el 4 de julio de 1549 se registra en Sevilla una misión de $2 I$ dominicos con destino a Cartagena al mando de Fr. José de Robles, la cual llega a la ciudad a finales de septiembre del mismo año, llevando consigo aceite para la lámpara del Santísimo Sacramento, vino de consagrar, un cáliz y campanas

20 FRIEDE, Op. Cit., p. 152

2I SAMUDIO TRALLERO, Alberto. Convento de Santo Domingo. Investigación histórica. Proyecto de restauración para el convento de Santo Domingo en Cartagena. Agencia Española de Cooperación Internacional, Arquidiócesis de Cartagena, Cartagena, Junio 22 de 200I. Pie de página No. 3

22 BÁEZ, Op. Cit., Tomo VI, Folio II

23 Ibíd., Tomo Vl, f. 15

24 FRIEDE, Op. cit., p. 158

25 ZAMORA, Op. cit., p. 20 
que le habían sido otorgadas por la corona. Este año llegan a Cartagena I4 frailes más (Ver Cuadro 2.) Desde el momento de su llegada, inicia la gestión de un solar para el convento que ya se tiene de tiempo atrás como residencia misional y que se ha intentado construir, se trata del primer núcleo conventual. Ariza menciona a continuación que el Deán Juan Pérez de Materano y el Cabildo, obsequian los solares y que se empieza la construcción en enero de 1550 en la plaza de la yerba ${ }^{26}$.

Cuadro 2. Dominicos llegados a Cartagena en 1549

\begin{tabular}{|c|c|}
\hline $\begin{array}{l}\text { Frailes que se registran en Sevilla } \\
\text { con destino a Cartagena }\end{array}$ & $\begin{array}{c}\text { Otros frailes que arribaron a } \\
\text { Cartagena }\end{array}$ \\
\hline José de Robles & Juan Méndez \\
\hline Rafael Segura & Francisco de Venegas \\
\hline Pedro Mellado & Lucas de Osuna \\
\hline Francisco López & Antonio de Sevilla \\
\hline Vicente Cerezo & Juan Suárez \\
\hline Cristóbal Ávila & Cristóbal Ojeda (Hno.) \\
\hline Francisco de la Parra & Juan de Ávila \\
\hline Juan de Berrío & Francisco de Carvajal \\
\hline Pedro Rubio & Francisco de Castro \\
\hline Nicolás de la Magdalena & Antonio Ruiz \\
\hline Luis de Mayorga & Jerónimo de Albear (o de Vidas) \\
\hline Diego de Palacios & Domingo de Cárdenas \\
\hline Alonso de Tapia & Juan de Zea \\
\hline Pablo Góngora & Juan de Chaves \\
\hline \multicolumn{2}{|l|}{ Luis Ortiz } \\
\hline \multicolumn{2}{|l|}{ Alfonso López } \\
\hline \multicolumn{2}{|l|}{ Pedro de Veras } \\
\hline \multicolumn{2}{|l|}{ Domingo Valverde } \\
\hline \multicolumn{2}{|l|}{ José de Santa María } \\
\hline \multicolumn{2}{|l|}{ Gonzalo Gutiérrez } \\
\hline \multicolumn{2}{|l|}{ Pedro de Tamayo } \\
\hline \multicolumn{2}{|l|}{ Francisco de la Resurrección } \\
\hline TOTAL 22 & TOTAL I4 \\
\hline
\end{tabular}

Fuente: ARIZA S., Alberto. O. P. Los Dominicos en Colombia. Bogotá, Provincia de San Luis Bertrán, 1992. Tomo I. pp. 240-243.

Un año de intensa gestión fue 1550 para el dominico José de Robles: intercambió correspondencia con la autoridad real, envió informes y solicitudes con el propósito de conseguir el apoyo de las misiones y la construcción de conventos, entre el que se cuenta el de San José en Cartagena. El 3 de enero de I550 Fray José de Robles comunica al Rey de su llegada al puerto y le informa sobre la necesidad de la instrucción de los indígenas y construcción del monasterio, en lo cual ya ha empezado a trabajar, cinco meses después, el 7 de junio de 1550 recibe respuesta:

$26 \quad$ ARIZA, Op. Cit., pp. $240-243$ 
"Devoto padre frai Josephe de Robles de la Orden de Santo Domingo: vi vuestra letra de tres de enero deste año por donde entendí vuestra llegada a essa tierra con los religiosos que con vos fueron y la necesidad que en ella hay de la doctrina cristiana e instrucción y conversión en los naturales della y de la voluntad que para este efecto tenéis y como lo comenzabais a poner en ejecución y en dar orden en hacer monasterios de lo cual todo hemos holgado y os lo agradecemos y tene mos en servicio y en ello mostráis bien el celo que tenéis al servicio de Dios nuestro señor y salvación de las animas de esos naturales que es como de vuestra religión y buena doctrina se espera y así somos cierto que con ella haréis mucho fruto y os encargamos prosigáis lo que habéis comenzado procurando por todas las vías que pudiereis de traer a esas gentes al reconocimiento de nuestra santa fe católica adoctrinándolos y enseñándolos en ella para que se salven y vivan en policía y razón y buenas costumbres, que yo escribo sobre ella al nuestro gobernador y oficiales desa tierra que os ayuden y favorezcan como vereis por mi carta que va con esta, vos nos avisaréis siempre de lo que conveniere que mandemos proveer para el bien dessa tierra y naturales de ella"27.

El la misma fecha, la Corte informaba al Gobernador de la Provincia de Cartagena, que como el Deán había dado a los dominicos una huerta de su propiedad, la cual el Cabildo ensanchó con otros solares, se les ayudara en la consolidación de su convento e iglesia, como se anota a continuación:

"Nuestro gobernador de la Provincia de Cartagena: ya sabéis como frai Joseph de Robles de la orden de Santo Domingo con otros religiosos de su orden están en esa provincia para emplearse y hacer fruto en la instrucción y conversión de los naturales de ella que tienen tanta necesidad el cual nos ha hecho relación que vista que en esa ciudad de Cartagena hay que se haga en ella un monasterio de su orden y el fruto de ello se siguiera, el dean de la iglesia catedral de ella les ha dado en limosna una huerta y sitio suyo que está en lugar cómodo y a propósito para fundar en él dicho monasterio y que así mismo el Cabildo de esa ciudad les ha dado junto al dicho sitio ciertos pedazos de tierra para el dicho efecto, suplicándonos se lo mandásemos confirmar para que desde luego se comenzáse a edificar la dicha casa o como la mi merced fuese y porque nosotros deseamos que en todo lo que hubiere lugar los dichos religiosos sean favorecidos y ayudados, os mando que veais los sitios y así el Cabildo de esa ciudad y el dicho déan dizque han dado a los dichos religiosos en que puedan edificar el dicho monasterio y siendo sin perjuicio de los indios ni de otra persona alguna, proveáis en ello lo que convenga de manera que lo que para ello se les hubiere de dar, no se siguiendo de ello perjuicio a nadie según dicho es, sea moderada cantidad"28.

En diciembre de 1550, Zamora menciona que una vez asignados los religiosos necesarios y enviados otros a los pueblos de la Gobernación de Cartagena y Santa Marta, Robles parte a Santa Fe en el mes de diciembre de $1550^{29}$. La segunda etapa, cuya cronología abarca un corto período (I549-1550) puede llamarse de formalización del núcleo conventual, una etapa que se fortalece con la llegada de nuevos frailes, con el reconocimiento de las autoridades civiles y eclesiásticas de la erección material del convento y de la labor de adoctrinamiento de los indígenas llevada a cabo por los frailes. Ya se ha dicho que la obra

AGI, Santafé, 987, Tomo III, f. I7 v

AGI, Santafé, 987, Tomo III, f. 21

ZAMORA, Op. Cit., Tomo II, p. 36 
inicia en 1550 en la plaza de la Hierba; sin embargo consideramos que aún no se puede hablar verdaderamente de una etapa constructiva pues, como veremos más adelante, se registra un nuevo emplazamiento acompañado de un largísimo proceso constructivo.

\section{Tercera etapa: Inicio de la etapa constructiva (1550-1552)}

La obra material que empieza a levantarse en enero de 1550 por iniciativa de Robles, se trunca un año después, cuando se tiene noticia que hasta el 8 de enero de $155 \mid$ permaneció el modesto convento en la plazuela de la hierba, esta información ha sido extraída de la Noticia Historial de la Provincia de Cartagena de Indias escrita en I77I por Diego de Peredo, quien agrega además que en la misma fecha, el convento es trasladado al lugar que ocupa actualmente; Peredo menciona que a la fecha ocupaba el Priorato el Padre Fr. Diego Ramírez, la Vicaría General el Padre Fr. José de Robles y el Obispado don Fr. Francisco de Santa María Benavides ${ }^{30}$.

Esta es una razón que induce a Enrique Marco Dorta a establecer la fecha de 1552, por único indicio de la erección del convento de San José en Cartagena, amparado especialmente en el aspecto material arquitectónico. Dorta excluye cualquier indicio del núcleo conventual en 1539, aduce incongruencias históricas por parte de quienes lo han estudiado y por la falta de datos que dieran cuenta de su emplazamiento y factura en una fecha anterior a $1552^{31}$.

Esta cronología, de la cual nos hemos valido con el único propósito de estudiar las etapas constructivas del edificio conventual termina en febrero de 1552, año en el cual se registra un incendio que destruye la ciudad. Esta coyuntura y la donación de un solar por parte de Francisco Lipar, motivaron la reubicación del convento al lugar en que está hoy día. Es a partir de este momento que inicia el proceso constructivo del conjunto monumental dominicano en Cartagena de Indias.

\section{Línea del tiempo en la que se registran las etapas de construcción del edificio conventual}

1539: Pequeña iglesia con vivienda acomodada para los frailes por iniciativa de Fray Jerónimo de Loaisa.

Enero de 1550: Inicio de construcción de la casa y convento por iniciativa de Fray José de Robles.

Enero de I55 I: La construcción del convento e iglesia se detienen.

Febrero de 1552: Traslado a su definitivo emplazamiento, motivado por un incendio que destruyó la ciudad el 19 de febrero, con el propósito de reemprender la construcción, aprovechando un solar donado por Francisco Lipar².

30 PEREDO, Diego de. Noticia Historial de la Provincia de Cartagena de Indias. Biblioteca Nacional, Fondo Libros raros y curiosos, Tomo 160, I77I. Este autor es citado por Ariza, Báez y Urueta. Dorta por su parte, aunque menciona esta fuente, la refiere a un autor desconocido. Enrique Marco Dorta, Cartagena de Indias, puerto y plaza fuerte. Bogotá, Fondo Cultural Cafetero, 1988. p. 35

31 Ibíd., p. 36

32 Los datos del incendio y donación de terreno por Lipar, se encuentran en el Informe del Factor Real Juan Velásquez, 25 de junio de 1552. AGI, Santafé, 187, f. 55. Citado por Ariza, Op. Cit., p. 243 
Marzo de 1557 - junio de 1558: No se registran avances en las obras, Ariza menciona que todavía el 5 de marzo de 1558 y el 21 de junio del mismo año, la Real Audiencia urgía auxilios para la construcción del convento e iglesia ${ }^{33}$.

1565: En esta fecha el Prior Fr. Pedro de Mártir Palomino, ante la necesidad de nueva fábrica, distribuyó la predicación de cuaresma, enviando a San Luis Bertrán a Veragua y Nombre de Dios en Panamá y a Riohacha al fraile Jerónimo de Barros, con el fin de recoger dinero con el fruto de sus sermones y alguna limosna para empezar la construcción del edificio ${ }^{34}$. Aunque este asunto trata más bien de un aspecto relacionado con la financiación, se le ha querido tener en cuenta en la etapa constructiva del conjunto monumental, para tener una idea de lo que ocurría en aquel entonces y evitar dejar sin cubrir un período de veinte años ( 1558 a I578) en el proceso de elaboración de esta cronología constructiva. Sin embargo, lo hasta aquí anotado, no refleja más que los innumerables esfuerzos realizados por los dominicos para proyectar el convento cartagenero y la lentitud extrema con que se recorría cada paso en la búsqueda de su definitivo desarrollo arquitectónico.

1578: Según refiere Ariza, la obra se inició por fin en $1578^{35}$.

I578-79: Inicio de la obra.

IMAGEN 4. Fotografia del frontis de Santo Domingo: Portal y torre del templo. Arquitecta Liliana Rueda Cáceres, Cartagena, 2009. Tomada de "Conventos Dominicanos que construyeron un país" Bucaramanga: USTA, 2010

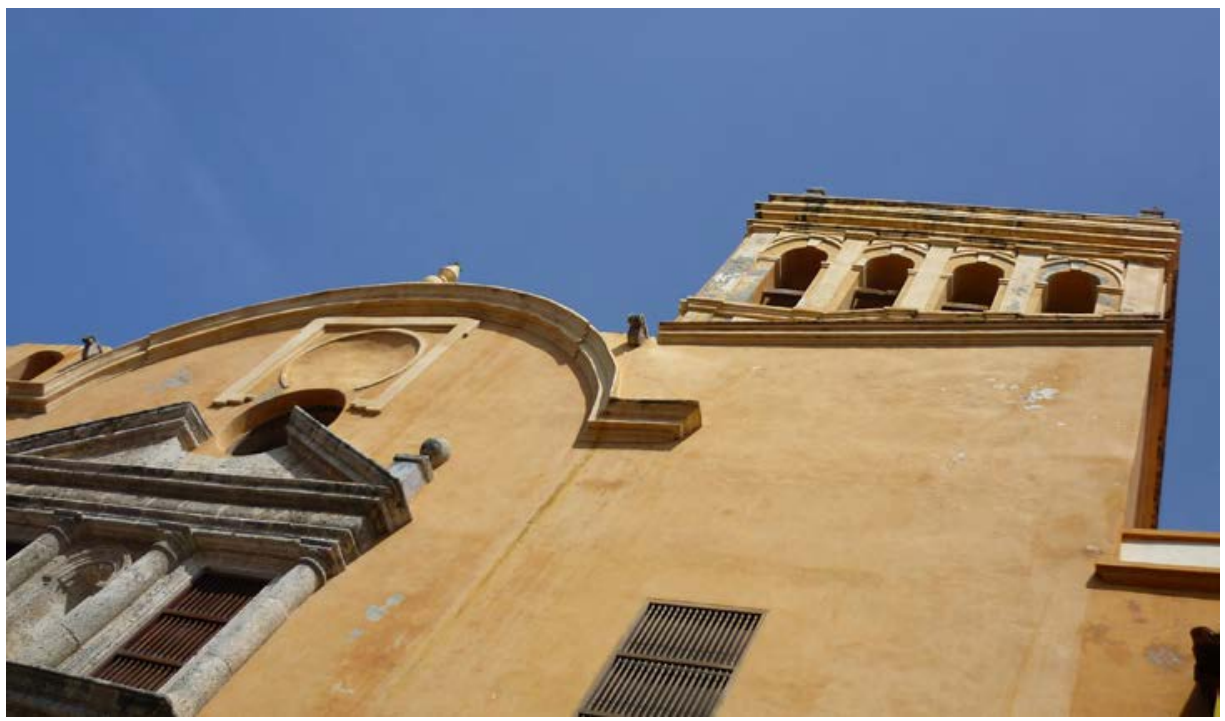

I579: Juan Luis Isaza Londoño menciona que en este año, el gobernador don Pedro Fernández de Busto notificó el inicio de las obras. En 1580 cuando ya los muros superaban el nivel del cimiento, arribó a la ciudad el fraile dominico Esteban de Ovalles a quien según parece se atribuye la mayor parte de la obra ${ }^{36}$.

1580: Aún no estaba hecha ni la mitad de la iglesia, en el cuerpo del templo las paredes estaban sacadas fuera de los cimientos hasta un estado sobre la tierra en algunas partes y en otras, arrasadas con la tierra; los cimientos de la capilla mayor (presbiterio) aún no estaban abiertos. Los oficios religiosos se hacían bajo un techo cubierto y la vivienda de

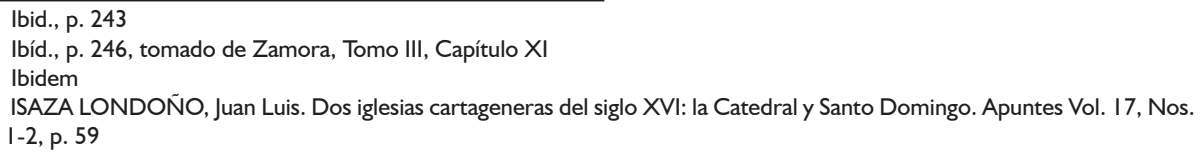


los religiosos era un corredor cubierto de tablas donde había solo 7 celdas ${ }^{37}$. La situación de la construcción para 1580, se puede complementar con el informe que rinde al Rey el obispo de Cartagena Fray Juan de Montalvo:

"El edificio de esta iglesia comienza ya a subir porque está hecha la capilla mayor y las colaterales y cubierto todo de allí adelante hay cuatro arcos de cada parte hechos de la nave de medio y descubiertos y las paredes de los lados se van levantando"38.

I58 I: En este año seguía edificándose el convento, en la tasación hecha por Drake de los edificios existentes en esa época para cobrar su rescate de la destrucción, aparece avaluada la obra en la suma de tres mil cuatrocientos cuarenta y cinco pesos, en tanto la catedral en treinta y dos mil setesientos seis pesos ${ }^{39}$.

1582: Buena parte de los muros y portada están hechos y aunque se desconoce el avance y el estado de las obras, se sabe que con el ataque de Drake en I586, la estructura sufrió notablemente. El 24 de noviembre de 1588 por Real Cédula se concedió una ayuda de 500 patacones para reparar los daños causados por el corsario ${ }^{40}$. Los dominicos pidieron licencia para traer a Cartagena dos esclavos negros, uno carpintero y otro albañil, a fin de emplearlos en las obras del monasterio ${ }^{41}$. Su petición se respondió favorablemente en $1594^{42}$.

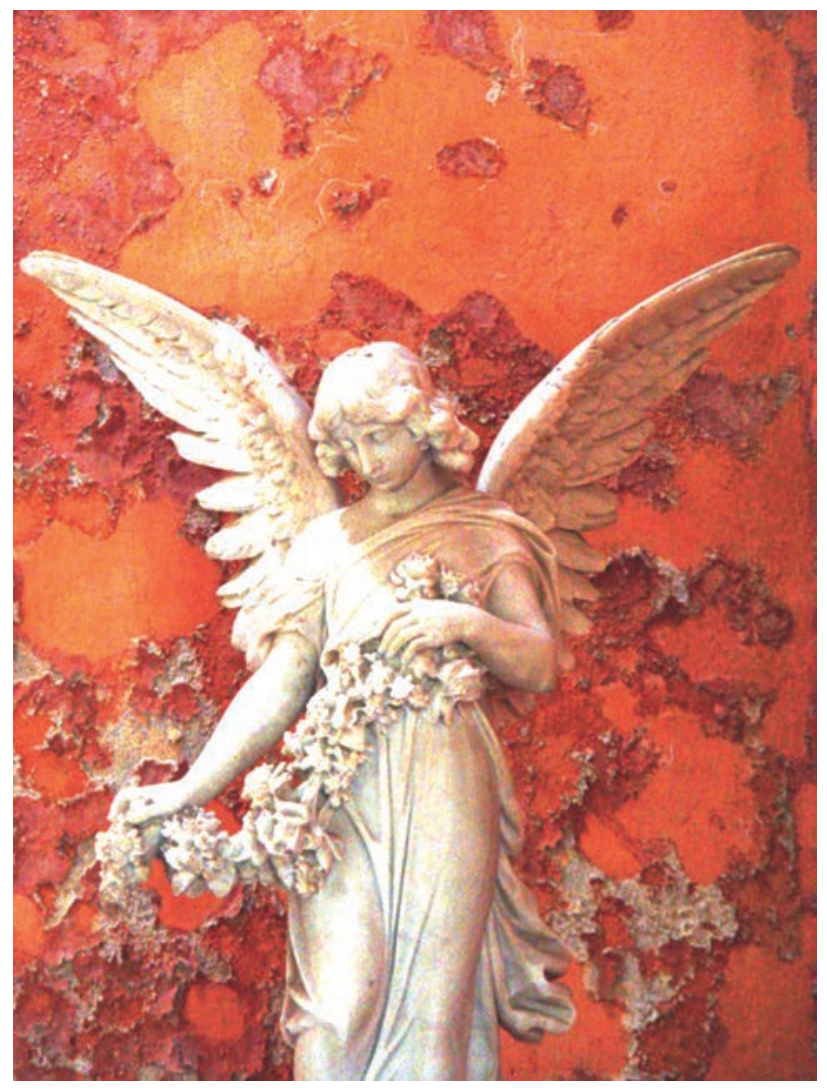

\footnotetext{
ARIZA, Op. Cit., p. 246
}

Reg 7614 - Fondo San Antonino, Sección: Conventos, Subsección: Cartagena, I580. (3/2/29) f. 0024.

AGI, Santafé, f. 62. Tomado de SAMUDIO TRALLERO, Alberto.

ISAZA LONDOÑO, Op. Cit., p. 59; ARIZA., p. 246

SAMUDIO TRALLERO, Alberto. Op. Cit., S.N.

2 Informe del Consejo de Indias del 12 de octubre de 1594, citado por SAMUDIO quien lo toma de la obra de Dorta, Cartagena de Indias: La ciudad y sus monumentos, Sevilla, I95I. p. 42
IMAGEN 5. Imagen religiosa de la Iglesia de Santo Domingo. María Fernanda Reyes Rodríguez, Cartagena 2010. 
IMAGEN 6. Planta primer piso convento

Santo Domingo de Cartagena - Dibujo Oscar Leonardo Millán García, estudiante USTA Bucaramanga a partir de planos de levantamiento realizados con anterioridad al proceso de restauración, suministrados por el arquitecto Alberto Samudio Trallero. Tomada de "Conventos Dominicanos que construyeron un país" Bucaramanga: USTA, 2010
1596: Ante una nueva solicitud de fondos por parte de los dominicos para continuar la obra, el Rey ordenó al gobernador mediante Real Cédula del 17 de mayo de 1596, que de los fondos otorgados a la construcción de la Catedral, una vez terminada, se dejase el repartimiento establecido para costearla, destinado su importe hasta por una cantidad de 5.000 pesos, para terminar la construcción de los claustros de San Agustín y Santo Domingo ${ }^{43}$.

16 1 2: Fray Esteban de Ovalles proseguía la obra con empeño; menciona Ariza que al parecer tuvo roces con el visitadorr Alonso de Almería, lo que lo olbigó a irse a Tolú donde murió a los 90 años de edad.

1620: En esta fecha los muros de la iglesia estaban enrasados y únicamente faltaba la cubierta, la cual por falta de fondos, sólo se terminó hacia 1630. En la misma época, Gonzalo de Herrera, marqués de Villalta, donó dinero ( 15.000 según Ariza) con el cual se construyeron los cuatro gruesos arcos transversales que reforzaron la estructura de la cubierta, la cual amenazaba ruina. Posteriormente fue necesario reforzar la fachada lateral exterior con cinco gruesos contrafuertes, que finalmente estabilizaron la estructura y que dieron el nombre a la calle sobre la que aparecen como Callejón de los Estribos ${ }^{44}$.

1639: En esta fecha, siendo provincial fray Luis de Colmenares, se hicieran las capillas del lado del Evangelio y tanto éstas como las de la Epístola se abovedaron, abriéndose además comunicación entre ellas, ya que solamente la tenían con la nave central ${ }^{45}$.

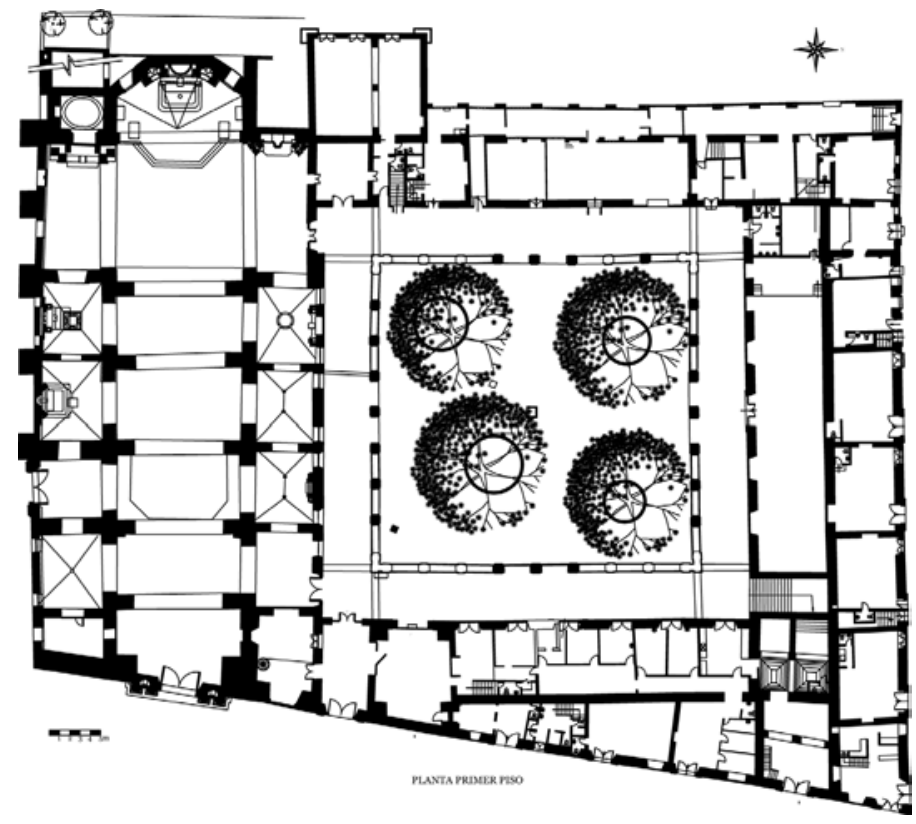

1647: Durante el primer provincialato de fray Alonso de la Bandera, siendo Prior del convento, fray Gabriel Ramírez, se empezó el aljibe.

43 SAMUDIO TRALLERO, Alberto.

44 ISAZA LONDOÑO, Op. Cit., p. 59

45 SAMUDIO TRALLERO, Alberto. 
1654: Desde esta fecha en adelante, se construyó la torre y portería, siendo Prior Alonzo Lazo y Provincial Fray Alonso de la Bandera ${ }^{46}$. Para Tulio Aristizábal Giraldo, la torre y portada son elementos que le dan perfección y hermosura al conjunto; considera que ésta última es una de las mejores que tiene la religión. Aristizábal infiere que esto debió ocurrir doblada ya la mitad del siglo ${ }^{47}$.

1695: Aún no se terminaba el primer claustro ${ }^{48}$.

1697: Al finalizar el siglo XVII aún no habían sido terminados sus claustros y dormitorios porque ningun prior se hallaba con caudal para proseguir el tercer claustro, en que la dejó el padre maestro fray Mateo de Valenzuela. En 1697 en un asalto propiciado por filibusteros, prendieron fuego a unos barriles con pólvora al interior del convento, que derribaron muros y destruyeron los altares ${ }^{49}$.

1725: Solicitud de los dominicos al Rey para pedir limosnas en el Perú con el fin de reedificar la iglesia, el coro y el convento, los cuales amenazaban ruina por la antigüedad y falta de mantenimiento, además mencionan en la solicitud no poseer coro donde asistir a las horas canónicas, ni habitaciones suficientes para albergar a los religiosos ${ }^{50}$.

1730: Según refiere Ariza, el 26 de febrero de 1730 el Rey autoriza limosnas en el Perú para reedificar el coro, la iglesia y el convento; ésta información se encuentra en la obra del Padre Báez, en la cual se refiere que por medio de la Real Cédula dada en Sevilla el 26 de febrero de 1730, se autoriza a los dominicos, pedir limosnas para reedificar el convento de Cartagena por estar muy viejo y no tener Coro ${ }^{51}$.

1740-1749: El gobernador de Cartagena ocupa el convento con las tropas de los Reales Ejércitos, se causaron grandes destrozos. La ocupación del recinto hacía parte de una estrategia militar implementada por las autoridades en pro de la defensa de la plaza, ante el inminente asalto a manos de sir Edward Vernon a la ciudad como consecuencia de la declaración de guerra hecha por el gobierno inglés a España el 23 de octubre de 173952 .

1766: El Convento reconstruía su edificio, pero para ello no tenía ningún dinero ${ }^{53}$.

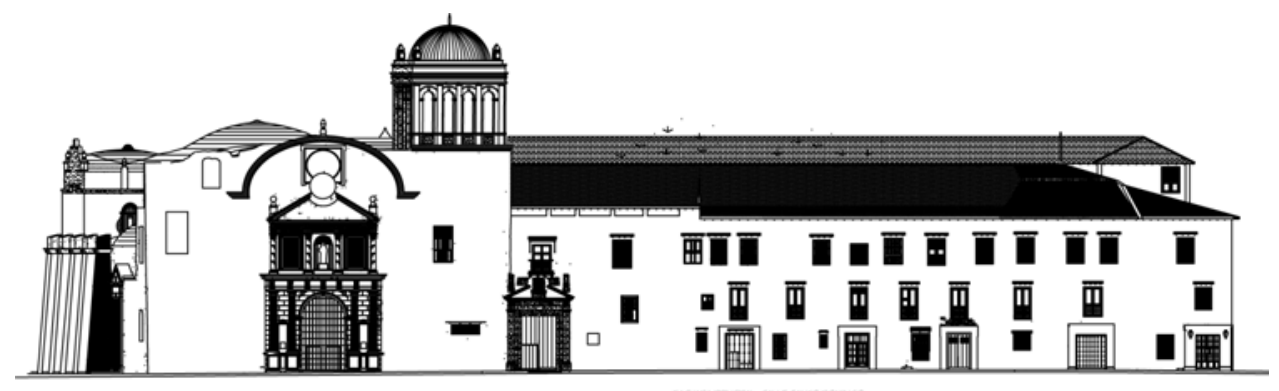

IMAGEN 7. Fachada principal - Dibujo Óscar Leonardo Millán García, estudiante USTA Bucaramanga a partir de planos de levantamiento realizados con anterioridad al proceso de restauración, suministrados por el arquitecto Alberto Samudio Trallero. Tomada de "Conventos Dominicanos que construyeron un país" Bucaramanga: USTA, 2010

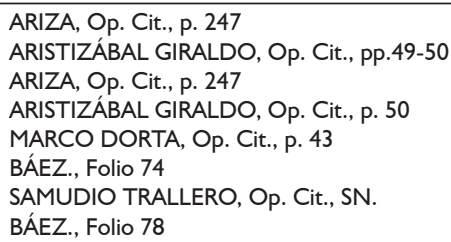


1796: El 3 de noviembre de 1796 se posesiona como superior del convento fray Juan Antonio de Buenaventura. Bajo su priorato se refacciona parte del convento, el paramento de la iglesia y el de la sacristía. Consigue gestionar de la Real Hacienda la suma de 7.538 pesos que emplea en la reparación de los daños ocasionados por la permanencia de la tropa en el convento ${ }^{54}$.

La descripción del hecho constructivo permite establecer lo desgastante del proceso que ha tardado más de dos siglos y cuya terminación está signada, más que por el adelanto de la obra arquitectónica, por conflictos políticos que derivaron en la supresión del convento y posterior traslado de los dominicos que quedaban en él hacia la diócesis de Santa Marta en 1833.

Como ya lo hemos referido en líneas anteriores, fue el incendio ocurrido el 19 de febrero de 1552 y la donación de un terreno por parte de Francisco Lipar lo que motivó el traslado del convento dominico al lugar que actualmente ocupa. Tomada esta fecha como punto de referencia, en lo que al menos respecta a su arquitectura, y anclados en I833, momento en el cual los dominicos son segregados y se proponen de nuevo arreglos y mejoras para poner en funcionamiento el Seminario de San Carlos (1835), es preciso insistir en el largo y desgastante proceso constructivo que se traduce en cifras a $28 \mathrm{I}$ años.

\section{Materiales de construcción}

La caña y la paja, materiales empleados por los indígenas fueron usados en las construcciones que se emprendieron desde la llegada de los españoles a Cartagena en I533. En I552 año en que se registró el incendio, la ciudad fue arrazada casi en su totalidad, razón por la cual se reconstruyó, con materiales más perdurables como el bahareque. El cambio en el empleo de materiales de construcción se atribuye al impulso dado a las obras públicas por el gobernador Pedro Fernández de Busto, cuya administración ejercida en dos períodos entre I57 I y I 586 fue decisiva en el progreso urbano de Cartagena. Se considera que fue en este período que se inició la transformación del pueblo de bohíos para dar paso a una ciudad con edificios de mampostería ${ }^{55}$.

El ataque de Francisco Drake a la ciudad y los incendios frecuentes ocurridos por entonces ponen a prueba una vez más, la poca durabilidad de los materiales constructivos, situación que obligó a las autoridades a recurrir a la piedra, tal y como se aprecia en el informe que rindió al Rey, Fray Juan de Montalvo, obispo de Cartagena en I580:

(...) y los negros se ocupan en traer piedra y cal los días de fiesta para venderla y este concierto tienen hecho con sus amos y este defiende el gobernador y díseme que ha de favorecerlos los edificios y a esta causa hay muchos negros que a tres años que están aquí y otros menos y otros más y por no les dar tiempo para catequizarlos no se bautizan ni veo medio para esto sino el que de Vuestra magestad viniere ${ }^{56}$.

54 MESANZZA, Andrés. Apuntes y documentos sobre la orden Dominicana en Colombia de 1680 a 1930. Caracas, 1936. p. 125

55 SAMUDIO TRALLERO, Alberto.

56 Archivo de la Provincia de San Luis Bertrán de Colombia. Reg $76 \mid 4$ - Fondo San Antonino, Sección: Conventos, Subsección: Cartagena, I580. (3/2/29), f. $025 \mathrm{~V}$. 


\section{Los constructores}

No se tiene un registro certero del arquitecto o alarife que pudo haber intervenido en la construcción del convento de San José en Cartagena de Indias. Algunos autores, atribuyen al cantero Simón González, quien en 1592 desempeñaba el cargo de maestro mayor de la ciudad, una posible intervención en la obra. En 1603 dirigió las obras del Convento de San Diego, que se terminaron en I625. Por la similitud de este claustro con los de Santa Clara, San Francisco y el Agustino de La Popa, Marco Dorta infiere que es muy posible atribuirle su autoría, al igual que la de la iglesia de Santo Domingo. Tampoco se tiene registro de la intervención de mano de obra indígena en el proceso constructivo propiamente, aun cuando sí del desempeño de algunas labores domésticas al interior del claustro. Los pocos registros con los que se cuenta, refieren la mano de obra esclava empleada en el proceso constructivo.

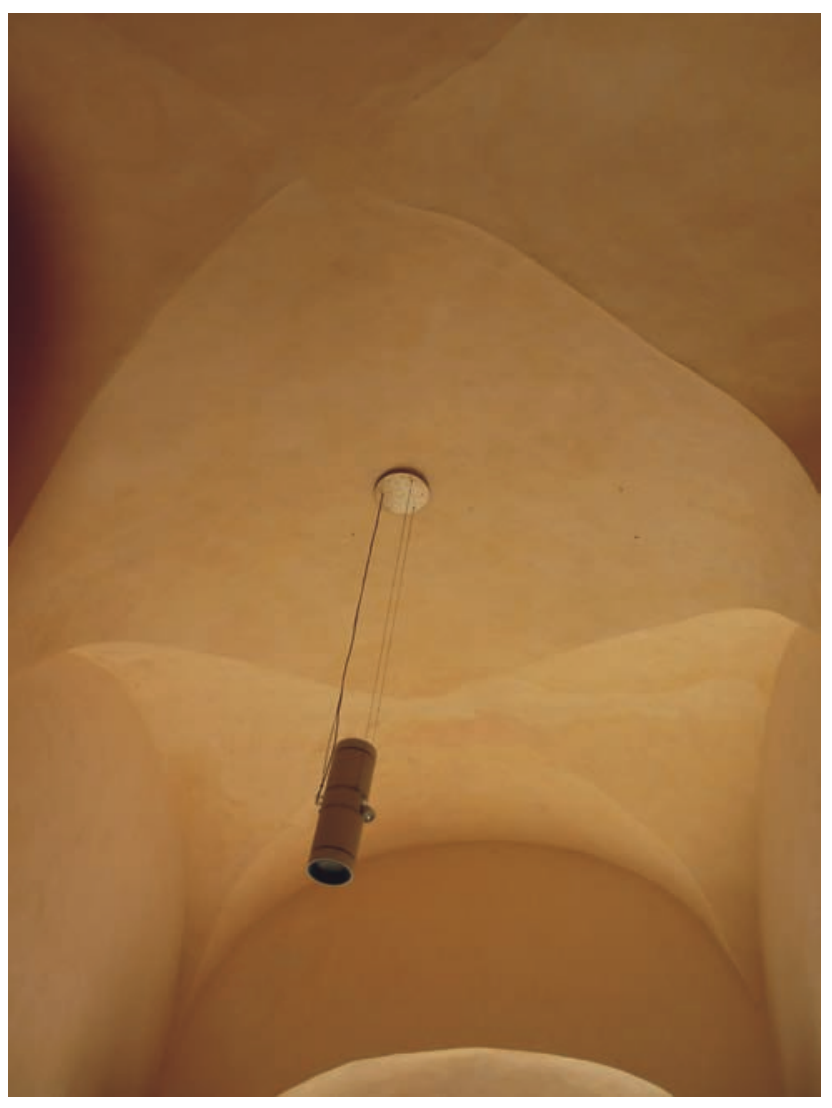

En I594 a raíz de la destrucción ocasionada por el asalto de Drake, los frailes del convento solicitaron se les diera licencia para traer dos esclavos, uno carpintero y otro albañil para reparar los daños y proseguir la construcción, petición que fue avalada por el Consejo de Indias ${ }^{57}$.

"En el año de 1616, se cayó el cañon de la iglesia de predicadores desta ciudad, que era de bóveda y encima estaba un negro del convento llamado Silvestre, cacanga de nación. Era albañil y cayó desde arriba y se quebró las canilla del muslo
IMAGEN 8. Detalle de la bóveda en portería. Arquitecta Liliana Rueda Cáceres, Cartagena 2009. Tomada de "Conventos Dominicanos que construyeron un país" Bucaramanga: USTA, 2010.

$57 \quad$ AGN, Santafe, I, N. III 
izquierdo por medio, junta a la rodilla y se le quebraron las gargantas de los pies ambos a dos y se quebró la muñeca y en la cabeza se quebró los cascos sobre la cien izquierda, en el hueso parietal se hizo una sub intración grande fractura y todo el cuerpo magullado y contuso y con muchas heridas en las espaldas"58.

En 1789 se invirtieron 500 pesos en la compra de esclavos para operar la hacienda del convento ${ }^{59}$.

El estudio arqueológico realizado en el Claustro de Santo Domingo sirvió para establecer no sólo las características estructurales de la edificación y sus posibles intervenciones a lo largo del tiempo, también arrojó información valiosa acerca de las prácticas realizadas por sus ocupantes. El hallazgo de tinajas de barro, material cerámico y restos óseos, permitió establecer aspectos de la vida cotidiana de los frailes y su espíritu de servicio, si tenemos en cuenta que el claustro fue usado como cementerio para un segmento de la población, lo que se relaciona con la vida monacal tanto en la cotidianidad como en la costumbre de enterrar a los muertos en los recintos sagrados. En este estudio se halló un cementerio infantil que se extiende desde el acceso principal del corredor al patio central hasta unos I5 metros hacia la entrada principal del convento; aunque la construcción de cementerios y la prohibición de inhumar los cadáveres en las iglesias fueron dispuestas en el último cuarto del siglo XVIII, en muchas ciudades esta práctica se desarrolló por la falta de recursos para el desarrollo de los cementerios o bien por rechazo a abandonar la piadosa costumbre de enterrar a los muertos en los atrios, iglesias y capillas conventuales y familiares o en cementerios anejos a las iglesias parroquiales ${ }^{60}$.

IMAGEN 9. Dibujo Óscar Leonardo Millán García, estudiante USTA Bucaramanga a partir de planos de levantamiento realizados con anterioridad al proceso de restauración, suministrados por la oficina del arquitecto Alberto Samudio Trallero. Tomada de "Conventos Dominicanos que construyeron un país" Bucaramanga: USTA, 2010.

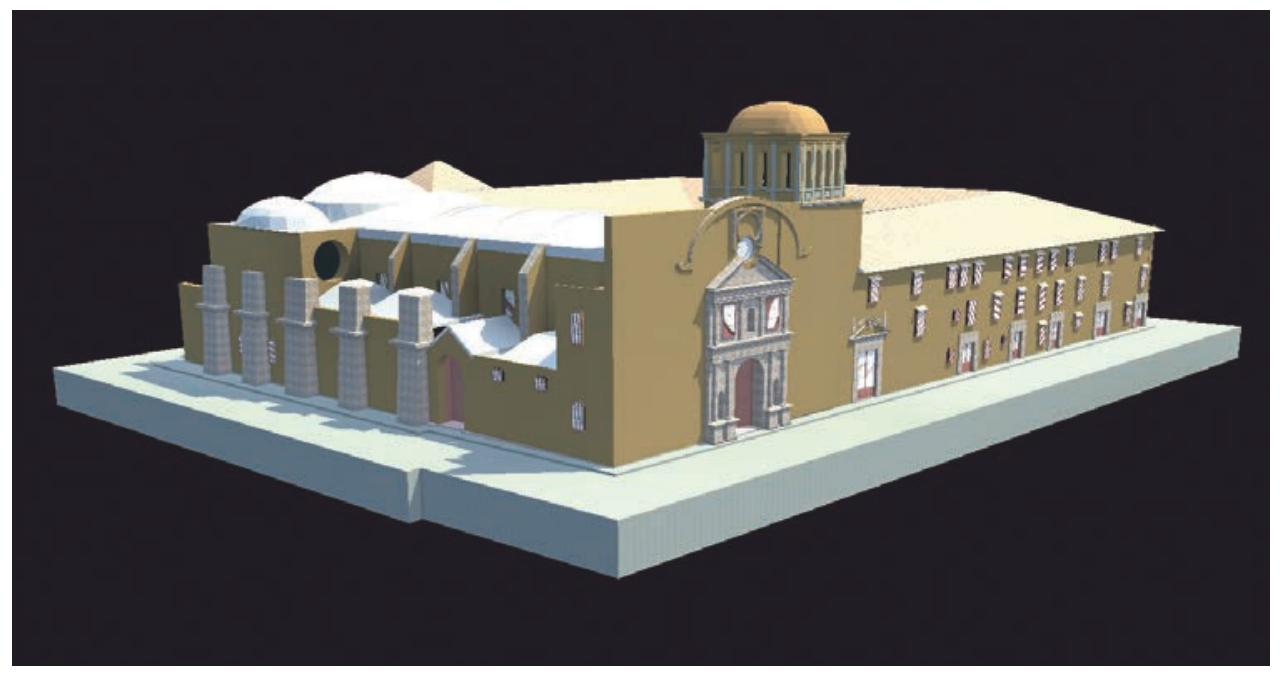

58 SOLANO ALONSO, Jairo. Salud, Cultura y Sociedad en Cartagena de Indias, Siglos XVI y XVII. Fondo de Publicaciones de la Universidad del Atlántico, Impreso en Bogotá, 1998. Citado por DÍAZ PRADO, Camilo. Historias desde el convento: La arqueología y la reconstrucción de la vida y muerte en el monasterio de Santo Domingo de Cartagena de Indias. p. II

59 Estado de capitales, réditos y misas. Archivo de la Provincia de San Luis Bertrán. Fondo San Antonino, Sección Conventos, Serie Estados Financieros, Subserie Cuentas, Caja 00I, Carpeta 000I, ff. 00I2-00I3, año I789

60 SALCEDO SALCEDO, Jaime. Urbanismo Hispano-Americano Siglos XVI, XVII y XVIII. El modelo urbano aplicado a la América española, su génesis y su desarrollo teórico y práctico. Bogotá, Centro Editorial Javeriano CEJA, 1996. Pie de página 66 de la página 170 


\section{CONCLUSIONES}

El proceso constructivo del convento de San José (Santo Domingo) en Cartagena de Indias, a cargo de la Orden de Predicadores fue largo y desgastante. La descripción del mismo permitió establecer que el proceso ha tardado más de dos siglos y que su avance está signado, más que por el adelanto de la obra arquitectónica, por conflictos políticos que derivaron en la supresión del convento y posterior traslado de los dominicos que quedaban en él hacia la diócesis de Santa Marta en 1833.

El proyecto de restauración realizado en el convento de Santo Domingo en Cartagena de Indias durante los años 2000 a 2004, a cargo del arquitecto Alberto Samudio Trallero con el patrocinio de la Agencia Internacional de Cooperación Española, abre la posibilidad de reflexionar sobre un destino semejante para otros inmuebles que aún quedan en pie en territorio colombiano. La función que hoy cumple el claustro restaurado, evidencia el desarrollo de un programa que garantiza su sostenibilidad como espacio del quehacer cultural y sirve de ejemplo a las administraciones locales de la manera correcta de recuperar los inmuebles de valor patrimonial.

\section{BIBLIOGRAFÍA}

ARISTIZÁBAL GIRALDO, Tulio. Iglesias, conventos y hospitales en Cartagena Colonial. Santa Fe de Bogotá, Banco de la República, El Áncora Editores, 1998.

ARIZA, Alberto. Los Dominicos en Colombia. Bogotá, Provincia de San Luis Bertrán, 1993.

BÁEZ, Enrique. La orden dominicana en Colombia (Obra Inédita) Paipa, 1950. Tomo VI. Conventos y casas dominicanas de Panamá, Cartagena, Santa Marta, Mompox, Riohacha, Valledupar, Tolú y Santo Ecce-Homo. Archivo de la Provincia de San Luis Bertrán de Colombia de la Orden de Predicadores. Bogotá, Fondo San Antonino, Sección personajes, Báez.

BARRADO BARQUILLA, José. (Editor). Los Dominicos y el Nuevo Mundo Siglos XVIIIXIX. Actas del IV Congreso Internacional Santafé de Bogotá, 6-I0 septiembre de 1993. Salamanca, Editorial San Esteban, 1995.

BORREGO PLÁ, María del Carmen. Cartagena de Indias en el siglo XVI. Sevilla, Escuela de estudios hispanoamericanos, 1983.

BUSHNELL, David. Colombia una nación a pesar de sí misma. De los tiempos precolombinos a nuestros días. Traducción de Claudia Montilla V. Bogotá, Editorial Planeta, 1996.

CIPOLLA, Carlos M. Cañones y velas en la primera fase de la expansión europea I4001700. Barcelona, Ediciones Ariel, 1967.

CONDE CALDERÓN, Jorge. Espacio, sociedad y conflictos en la Provincia de Cartagena 1740-18I5. Barranquilla, Fondo de publicaciones Universidad del Atlántico, Colección de ciencias sociales y económicas Rodrigo Noguera Barreneche, 1999.

CORRADINE ANGULO, Alberto. La arquitectura colonial. En: Manual de Historia de Colombia Tomo I. Bogotá, Instituto Colombiano de Cultura, 1978. 
DÍAZ PARDO, Camilo. La importancia de la Orden de los Predicadores en el contexto socio histórico de Cartagena. Barranquilla, Universidad del Norte, 2003.

DORTA, Marco. Cartagena de Indias. Puerto y plaza fuerte. Bogotá, Fondo Cultural Cafetero, 1988.

FRIEDE, Juan. La conquista del territorio y el poblamiento. En: Manual de historia de Colombia Tomo I. Bogotá, Instituto Colombiano de Cultura, 1978.

GARCÍA RUBIAL, Antonio. El convento: su función social. En: El convento Agustino y la sociedad novohispana 1533-1630. México, Universidad Nacional Autónoma de México, 1989.

ISAZA LONDOÑO, Juan Luis. Dos iglesias cartageneras del siglo XVI: La Catedral y Santo Domingo. Apuntes Vol. 17, Nos. I-2, pp. 50-63.

MONTAÑO CUÉLLAR, Jimena. El Convento de Santo Domingo. Biblioteca virtual Luis Ángel Arango, 200I.

RODRÍGUEZ FREYLE, Juan. El Carnero. Bogotá, Ediciones Nacionales, Círculo de Lectores.

RUEDA ACEVEDO, Orlando. Los dominicos y el arte en la evangelización del Nuevo Reino de Granada. En José Barrado Barquilla (Ed.) Los Dominicos y el Nuevo Mundo Siglos XVIIIXIX. Actas del IV Congreso Internacional, Bogotá, 6-10 septiembre de 1993. Salamanca, Editorial San Esteban, 1995.

SALCEDO SALCEDO, Jaime. Urbanismo Hispano-Americano Siglos XVI, XVII y XVIII. EI modelo urbano aplicado a la América española, su génesis y su desarrollo teórico y práctico. Bogotá, Centro Editorial Javeriano CEJA, 1996.

SAMUDIO TRALLERO, Alberto. Convento de Santo Domingo. Investigación histórica. Proyecto de restauración para el convento de Santo Domingo en Cartagena. Agencia Española de Cooperación Internacional, Arquidiócesis de Cartagena, Cartagena, Junio 22 de $200 \mathrm{I}$.

. Cartagena ventiún años después de ser declarada patrimonio mundial. Memorias. Revista Digital de Historia y Arqueología desde el Caribe. Año 3, No. 6, Uninorte, Barranquilla, Noviembre de 2006.

THERRIEN, Mónika. El espacio urbano de Cartagena en la colonia. Historia Crítica, No. 2, Bogotá, Julio-Diciembre de 1989. 
URUETA, José P.; GUTIÉRREZ DE PIÑERES, Eduardo. Cartagena y sus cercanías. Guía descriptiva. Cartagena, Tipografía de Vapor Mogollón, 1912.

VILLANUEVA CEREZO, Luis. Restauración del Convento de Santo Domingo en Cartagena de Indias. En: R\&R Restauración y rehabilitación No. 89, Julio de 2004. Revista Internacional del Patrimonio Histórico. España, Universidad Politécnica de Valencia, Instituto de Restauración del Patrimonio, América lbérica, 2004. pp. 22-27.

ZAMORA, Alonso de. Historia de la Provincia de San Antonino del Nuevo Reyno de Granada. Tomo II. Instituto Colombiano de Cultura Hispánica. Bogotá, Editorial Kelly, 1980.

\section{OTRAS REFERENCIAS}

Diccionario Geográfico-Histórico de las Indias Occidentales o América. Es a saber: de los Reinos del Perú, Nueva España, Tierra Firme, Chile y el Nuevo Reino de Granada. Escrito por el Coronel Don Antonio de Alcedo, Capitán de Reales Guardias Españolas, de la Real Academia de Historia. Tomo V. Madrid, Imprenta de Manuel González, I 789.

Historia de la vida, virtudes y milagros del Beato Luis Bertrán de la Orden de Predicadores. Por el P. M. Fr. Vicente Saborit, Regente de los estudios del Real Convento de Predicadores de Valencia. Dedicado al muy ilustre señor Don Pedro Quexal. Año de 165I.

\section{ARCHIVOS}

Archivo General de la Nación AGN

Archivo de la Provincia de San Luis Bertrán APCOP

Fototeca de Cartagena de Indias 